\title{
Por una ética del arquitecto; EI mall de Castro como caso (a)típico de nuestro actuar profesional.
}

Towards an architect's ethics; The Mall of Castro as an (a)typical case of our professional actions.

Sergio Salazar

\section{Filiación}

Universidad del Desarrollo, Chile

E mail: sergiosalazar@gmail.com

Primera versión recibida en: 15 de diciembre de 2013

Última versión recibida en: 27 de junio de 2014

\section{Resumen}

La construcción del famoso mall de Castro cambió dramáticamente el paisaje de la capital de Chiloé, en la $X$ región de Los Lagos. Esto constituye un dilema respecto a la preeminencia de las soluciones de equipamiento comercial que buscan mejorar la oferta de servicios para la comunidad, respecto a la conservación de una identidad local y los valores patrimoniales de su arquitectura. A su vez, el caso deja de manifiesto la inoperancia o baja incidencia de las herramientas creadas para cuidar el patrimonio construido, particularmente los planes reguladores y el Sistema de Evaluación de Impacto Ambiental (SEIA). Cabe preguntarse entonces: ¿Cuál debería ser la responsabilidad ética de los arquitectos en una transformación urbana que implica inevitable costos patrimoniales?

El artículo aborda la consecuencia del proyecto arquitectónico en su acción sobre un entorno urbano y natural, pero pone énfasis en la problemática derivada de la responsabilidad ética que tiene la figura del arquitecto, en cuanto ejerce un poder sobre el medio ambiente construido.

\section{Palabras claves}

Ética del arquitecto; patrimonio; planificación urbana.

\begin{abstract}
The construction of Castro's shopping mall dramatically changed the landscape of the landscape of the Chiloe Island's capital city. This fact represents the dilemma between the primacy of commercial equipment solutions, which seek to improve the services offered to the community, and the capability to recreate the identity and heritage values of local architecture. In turn, the case renders the low incidence of the planning tools that take care of the quality and history of the built environment (regulatory plans and environmental impact assessment studies), completely evident. This raises the following question: What should be the ethical responsibility of architects in an urban transformation that involves a significant impact on the local heritage?

The article discusses the consequences of the architectural project in its action on an urban and natural environment, emphasizing on the problems associated with having an ethical responsibility of the architect, as a relevant actor in the production of built environments.
\end{abstract}

\section{Key words}

Architect's ethics; heritage; urban planning. 


\section{URBANISMO}

ISSN 0717-5051

Revista de Urbanismo №30 - Enero - Junio de 2014

http://revistaurbanismo.uchile.cl Departamento de Urbanismo - FAU - Universidad de Chile

\section{Sumario}

Introducción

1 La sustentabilidad como responsabilidad ética

2 Hacia una ética del arquitecto.

Reflexiones finales.

Bibliografía

\section{Introducción}

"Ese arquitecto es empleado del empresario, no es un arquitecto independiente, también hay que entender eso... Es un siervo más que un empleado, y si no tiene muchos escrúpulos, si no tiene una fuerte formación ética, ese arquitecto va hacer lo que le pidan. No va a poner condiciones".

Sebastián Gray, Presidente Nacional del Colegio de Arquitectos de Chile ${ }^{1}$.

La construcción del hoy famoso mall de Castro cambió dramáticamente el paisaje de la capital de Chiloé, en la Región de Los Lagos. Nos ha hecho preguntarnos respecto de la preeminencia de las soluciones de equipamiento comercial que persiguen mejorar la oferta de servicios para la comunidad, respecto a la conservación de una identidad local y los valores patrimoniales de su arquitectura. El caso encarna una preocupación, cada vez más común entre las autoridades, respecto a la participación de la ciudadanía en las decisiones que afectan directamente a su calidad de $v \mathrm{da}^{2}$, a la vez que deja de manifiesto la inoperancia o baja incidencia de las herramientas supuestamente creadas para cuidar el patrimonio construido, particularmente los planes reguladores y el Sistema de Evaluación de Impacto Ambiental (SEIA ${ }^{3}$. Cabe preguntarse entonces: ¿Cuál sería la responsabilidad ética de los arquitectos en una transformación urbana que implica costos patrimoniales?

El caso del mall de Castro exige analizar la consecuencia del edificio como acción sobre un entorno ya no sólo arquitectónico sino natural; una problemática derivada de la responsabilidad ética que tiene la figura del arquitecto, en cuanto ejerce un poder sobre el medio ambiente. Es aquí donde ciertas aproximaciones teóricas, desde la ética, pueden iluminar la discusión.

La ética puede definirse como la teoría o ciencia del comportamiento moral de los humanos en sociedad $^{4}$. Para Aristóteles ${ }^{5}$, las virtudes éticas son aquellas que se desenvuelven en la práctica y van encaminadas en la prosecución de un fin, vinculadas al concepto de vida práctica, a un saber práctico donde el hombre en tanto ser social muestra acciones, puede elegir y demostrar conductas éticas y morales.

\footnotetext{
1 GRAY, Sebastián en ROMERO, Martín. "Presidente del Colegio de Arquitectos: Si el marco legal es laxo, el inversionista inmobiliario puede hacer lo que quiera". Entrevista publicada en http://colegioarquitectos.com/noticias/?p=4054 el 21/06/2013 consultado al 18/11/2013.

2 La consulta ciudadana realizada el 15 de abril del 2012 mostró que una importante mayoría de sus habitantes quiere el mall. Participaron en esta consulta 5.240 personas, de las cuales más de 4.800 (alrededor de un $95 \%$ de los votantes) se mostraron a favor de la construcción del centro comercial y sólo un poco más de 300 personas rechazaron la propuesta.

3 Es labor de la autoridad escuchar la opinión de los vecinos, y generar las herramientas que permitan cuidar un patrimonio arquitectónico innegablemente afectado por la acción de los privados, pero validado por un marco regulatorio generado por el estado. Aún queda por ver cuál será el impacto que la construcción del mall significará en la depreciación de comercio local o cómo afectará a la afluencia de turistas a la zona.

4 SÁNCHEZ 1981
}

5 ARISTÓTELES 2001 
Etimológicamente, ética, viene del griego ethos, significa costumbre y por eso se ha definido como la doctrina de las costumbres. Más tarde a través del latín se tradujo este concepto bajo la expresión mos, moris (de donde surge en castellano la palabra "moral"), que equivale únicamente a hábito o costumbre. Pero de igual manera, se le considera en su significado como, morada, hábitat, carácter, modo de ser. En este sentido, el concepto ha evolucionado y hoy se le reconoce como un conjunto de valores, como una posibilidad del hombre para alcanzar sus metas, movilizando sentimientos y voluntades ${ }^{6}$.

Por otra parte, la palabra 'profesión' deriva del latín, con la preposición pro, que significa delante de, en presencia de, en público, y con el verbo fateor, que significa manifestar, declarar, proclamar. De estos vocablos surgen los sustantivos profesor y professio, que remiten al acto de saberse expresar ante los demás. Con base en ello, puede decirse que la profesión es beneficiosa para quien la ejerce, pero también está dirigida a otros. En este sentido, la profesión tiene como finalidad el bien común.

A juicio del filósofo chileno Jorge Eduardo Rivera, si hubiese que escoger una única palabra qué exprese la idea de ética, esa palabra podría ser 'justicia'. Lo explica desde una de las fuentes más antiguas del término: la palabra griega diké: "Diké es el ajustamiento o ajuste de una realidad con otra, cómo calza la una con la otra"7. La ética es pues, la justeza o el ajuste de las partes de un todo, y la correcta articulación de las unas con las otras.

Para Rivera, la justicia ética, como forma de justeza o de ajustamiento, es el ajuste o el plegamiento de los actos del hombre a la realidad en la cual está inserto. Pero lo ético tiene también una dimensión en el sentido de los valores, de los deberes; una dimensión 'moral'. Por tanto, "es éticamente bueno lo que se hace respetando la realidad, es decir, ajustándose a ella. Y es éticamente malo lo que se hace sin respetar la realidad, violándola, esto es, actuando desajustadamente respecto de ella"s.

\section{La sustentabilidad como responsabilidad ética}

Desde una mirada aristotélica de la naturaleza, la comprensión del medio ambiente va más allá del entorno animal o vegetal. En el libro V de su Metafísica, Aristóteles dice: "La naturaleza, en este sentido, es el principio de movimiento de los seres naturales, inmanente a ellos, en potencia o en acto" 9 . De este modo, la construcción de la ciudad puede ser entendida como la concreción en acto de los principios que residen en el hombre en cuanto a potencia y que le determinarían como un ser natural tanto como su entorno.

La preocupación por la sustentabilidad como un imperativo a defender, constituye es propio de la arquitectura sustentable, La noción de un imperativo natural nos habla de una urgencia por el trabajo asociado a una valoración del entorno, ya no solo natural, sino producido o diseñado. El mall es un ejemplo de la responsabilidad de una construcción de escala mayor en un entorno natural, así como la importancia de sus consecuencias respecto de un bien mayor: el cuidado del paisaje y la preservación del patrimonio.

Toda decisión libre efectúa una voluntad, lo que Kant llama la buena voluntad, lo primordialmente bueno, y que refiere al motor que anima la ejecución de nuestras acciones y dispone de los dones de la naturaleza10. En el caso del mall Paseo Chiloé, las decisiones tomadas ponen en valor la preeminencia de los intereses comerciales de la ciudad por sobre el

\footnotetext{
6 BROWN 1998

7 RIVERA 2004

8 RIVERA 2004

9 ARISTÓTELES. Metafísica. Libro V. Citado por MORENO, Miguel. Historia de la Filosofía vol. 1. Universidad de Granada, 2010.

10 KANT 2005
} 
valor de su identidad, aun cuando el argumento de que Castro necesita un centro comercial que no obligue a sus habitantes a desplazarse, sea real y válido. El emprendimiento del privado y la iniciativa de la autoridad municipal se justifican políticamente, en cuanto es innegable que miles de ciudadanos demandan accesibilidad a nuevos servicios. Como declara Graciela Álvarez, presidenta de la Junta de Vecinos Blanco Encalada, el mall traerá consigo una importante fuente laboral al Archipiélago y contribuirá para que las familias de la zona tengan un lugar de esparcimiento. Ella afirma que: "el Colegio de Arquitectos se ha quedado callado respecto a los palafitos, que son auténticamente chilotes, pero sí se han dedicado destrozar el mall"11, expresando distancia entre el sentir popular y el juicio de los eruditos.

En este punto puede ser de ayuda introducir la mirada de algunos académicos que han reflexionado sobre los dilemas de la ética y la arquitectura. El académico estadounidense Warwick Fox en su libro Etichs of the build environment ${ }^{12}$ ha desarrollado este punto de la acción sobre entornos naturales y patrimoniales. El enfoque planteado por Fox guarda relación con la comprensión de la ciudad como parte del entorno natural y con ello, con el medio ambiente como construcción. En una idea: el patrimonio amenazado en Castro no es sólo su iglesia ${ }^{13}$, Monumento Nacional y Patrimonio de la Humanidad afectado por la proximidad del nuevo edificio, sino la continuidad y coherencia del paisaje (natural y construido), que se transforma ante la irrupción del mall.

El académico e investigador inglés John Whitelegg ${ }^{14}$, plantea que el entorno construido es un poderoso factor en la relación de cómo se distribuyen las externalidades de la vida cotidiana; aquello positivo o negativo que define nuestra calidad de vida. Es un hecho, dice Whitelegg, que la construcción de la ciudad contemporánea no está preocupada de generar ambientes sanos o bellos. A su juicio, el desafío ético que tenemos entre manos es valorar la importancia del paisaje ante la comunidad local, que permita reconocer los nexos emocionales y espirituales que nos ligan a un lugar, a fin de no ir actuando con el criterio a-ético con que usualmente algunos actores se aproximan a intervenir la ciudad.

Por otra parte, Mustafa Pultar ${ }^{15}$, investigador turco, académico de la Facultad de Arquitectura del METU (Middle East Technical University) de Turquía, propone una aproximación más crítica entre filosofía y práctica. Él plantea que hay dos tipos de valores: intrínseco y extrínseco. Los intrínsecos son los valores del objeto en sí y los extrínsecos son los de la relación del objeto con sus circunstancias. Sin embargo, advierte Pultar, cada persona ve diferente el objeto según su interés, y eso hace que los valores varíen. Por eso, no debiera sorprendernos que un enfático 95\% de los vecinos que votaron en la consulta del 15 de abril del 2012 lo haya hecho a favor del mall. Esto básicamente abre el debate sobre cuál es el rango de valores adecuado, y cómo asignarles una expresión que a través de indicadores objetivos, les permitan impactar en el diseño. ¿Cómo enfrentar diferentes voluntades o éticas sobre el entorno construido?

Quizá la respuesta esté en la suma de dos iniciativas: la definición de estándares y pautas para guiar la conducta (ética normativa), y la reflexión constante sobre los problemas de alcance moral, significativos y prácticos (ética aplicada). Ambas se dirigen hacia la construcción de regulaciones sociales. Y para alcanzar éstas es necesario el consenso.

11 ÁLVAREZ 2013, Graciela citada por NúÑEZ, María Eugenia en "Dirigentes sociales de Castro exigen la pronta apertura del mall chilote", publicado en SoyChile.cl el 12/06/, disponible en http://www.soychile.cl/Chiloe/Sociedad/2013/06/12/179861/Dirigentes-sociales-de-Castro-exigen-la-pronta-aperturadel-mall-chilote.aspx

12 FOX 2000

13 La iglesia llamada "San Francisco" pero popularmente conocida como catedral de Castro, es obra del arquitecto italiano Eduardo Provasoli. Fue construida a principios del siglo pasado y declarada Monumento Histórico Nacional en 1979, y Patrimonio de la Humanidad ante la Unesco el 30 de noviembre de 2000.

14 WHITELEGG, John. "Building ethics into the built environment" en FOX, W. (ed.) Ob.cit.

15 PULTAR, Mustafa. "The conceptual basis of building ethics" en FOX, W. (ed.) Ob.cit. 
La ética hace énfasis en la responsabilidad y en las conductas, las cuales deben ser comunicadas, deliberadas, discutidas para llegar a acuerdos con resultados y decisiones acertadas dentro de una sociedad. Lo anterior, lleva a enfocar la ética como un tipo de saber práctico preocupado por averiguar cuál es el fin de las acciones, para así decidir qué hábitos pueden asumirse, cómo ordenar las metas intermedias, cuáles son los valores que sirven de orientación, qué modo de ser o carácter van a ser incorporados, a fin de obrar con prudencia, es decir, tomar decisiones acertadas ${ }^{16}$. No se trata de crear leyes, pues la norma o el código no señalan las actitudes de las personas, ello surge de la combinación de estos factores, pero con la ética marcando la integración de los mismos.

Son las organizaciones quienes recogen estos consensos y tienen la posibilidad de actuar, desde las empresas, las municipalidades, y los colegios profesionales. A su vez la sociedad debe velar por que sus organizaciones tengan una misión y una visión dentro de su cultura local, revisando qué metas se les pide perseguir, y qué valores y hábitos deben incorporar para alcanzarlas. Las organizaciones, como parte de la sociedad, están llamadas a vincularse, cada vez más, a las exigencias que la misma requiere. Sociedad, organización e individuo deberán mantener un equilibrio de crecimiento y desarrollo que permita dar una imagen de integración, cooperación, colaboración y formación de los ciudadanos.

\section{Hacia una ética del arquitecto.}

¿Cuál es la ética que fundamenta nuestro oficio? ¿Existe una ética de la arquitectura? Consideremos que hay en toda ordenación jurídica un fundamento ético, que sin embargo no agota la dimensión ética involucrada en tal ordenación. Por ello es que existen comités de ética u organismos similares, cuyo ámbito va más allá de la ordenación jurídica. Esa relación éticaarquitectura está referida a un mundo que va más allá de lo normativo, en una tarea intimamente vinculada al pensar y al actuar del profesional.

Debemos tenerlo claro: el quehacer del arquitecto impacta en la vida del grupo social en que se inserta su obra. Debe, por tanto, sopesar sus actos conforme a cómo sería el mundo si todos actuaran como él. Parafraseando a Germán del Sol, cuando refiere al trabajo de Álvaro Siza en el proyecto del restaurant Boa Nova, en que el arquitecto portugués construye sobre un escarpado roquerío junto al mar: "Podría haber dinamitado las rocas, y construido encima lo que viniera a su antojo. Pero, conforme a la ética que hemos descrito, opta por aprovechar lo que el paisaje le ofrece, no para imitarlo, sino para articular su proyecto en torno a él"17. Se establece un diálogo con lo que las cosas son en esencia, asunto dado por un fuerte sentido de la responsabilidad con el lugar en lo que supone es 'hacer arquitectura'.

Podemos continuar recordando a un arquitecto chileno, el recientemente fallecido Alberto Cruz. Con ocasión del diseño de una población obrera para 50.000 personas en Achupallas, V región, en el año $1953^{18}$, Cruz escribe el siguiente texto:

"... Bienes: el mar, el árbol, la tierra, el cielo... supongamos que se forma un jardín perfecto... urbanización-arquitectura-organización... y todo sea perfecto... ¿qué se ha ganado?... se ha ganado esto. Que los 50.000 vivan dichosos en su paraíso... Valparaíso/Paraíso... ¿Pero es ésta la labor del urbanista? ¿Es ésta su sola empresa? El

16 CORTINA 1999

17 DEL SOL 2013

18 Se trataba de un estudio que el Instituto de Arquitectura UCV había realizado paralelamente al encargo profesional recibido por la oficina de Sergio Larraín y Emilio Duhart en Santiago. Ninguno de los dos proyectos, ni el de Duhart ni el del Instituto de Arquitectura, llegaron a realizarse. 
urbanista descubre el destino de la ciudad y lo coloca en el espacio, para que la ciudad y sus habitantes vivan su destino, sea éste suave o duro, heroico o no heroico?"19.

El texto podría mal leerse como "un arquitecto que se aboga poderes sobrehumanos: poderes de dominación sobre los ciudadanos"20. Sin embargo, también es posible leerlo como un arquitecto que, consciente de que su oficio implica una forma de poder, debe procurar no ejercerlo como tal. Su ejercicio debe ofrecerse como una forma de donación. En esta lectura, 'poder' puede ser leído como 'regalo' y 'destino' como 'sentido'. Así, la 'labor del urbanista', esto es su oficio, queda orientado por el descubrir el sentido de la ciudad y su colocación en el espacio. Esa colocación tomará forma de plan, diseño o forma.

La atención de Cruz sobre el destino/sentido de la ciudad, pone en relieve la vocación de una arquitectura al servicio de otros. Esta es una dimensión del problema que por común se olvida: que el arquitecto trabaja con una materia que en muchos sentidos es de otros. La finalidad a que se dirige es, en definitiva, la vida de otros. Sin duda tal condición marca una cierta ética naturalmente excéntrica, en que no cabe hacer como solo para sí lo que es intrínsecamente para otros.

\section{Reflexiones finales.}

La ciudad puede ser interpretada como un ser vivo, un organismo constituido por diferentes sistemas que se articulan en beneficio de un todo. Por esencia, la ciudad tiende al bien o persigue el bien. Como señala Aristóteles:

"Ya que vemos que cualquier ciudad es una cierta comunidad, también que toda comunidad está constituida con miras a algún bien es evidente. Así que todas las comunidades pretenden como fin algún bien; pero sobre todo pretende el bien superior, la que es superior y comprende a las demás. Esta es la que llamamos ciudad y comunidad cívica"nl.

Sin embargo, la condición urbana contemporánea tiende a ser el resultado de una suma de factores cercanos a lo político, económico y funcional más que una búsqueda del bien común. En este escenario una herramienta para generar cambios puede ser la participación ciudadana, sin embargo su éxito se ve dificultado con la pasividad de los propios vecinos o la negativa de las autoridades a gestar mayores espacios de diálogo. En el caso del mall de Castro la consulta ciudadana, si bien fue exitosa en la convocatoria (más de 5.000 personas) simplemente llegó $\operatorname{tarde}^{22}$.

Ante el arquetipo de la ciudad moderna ${ }^{23}$, cargada de intervenciones confusas, surgen de vez en cuando preocupaciones por la preservación de la identidad local. Sin embargo, muchas veces estas preocupaciones se incorporan en los proyectos con un argumento que tiende a

19 CRUZ, Alberto. Citado por PÉREZ, Fernando. "Ética, Ciudad y Arquitectura" en BALCELLS, I., RIVERA, J.E., VIAL, J, PÉREZ, F. Ética, Ciudad y Arquitectura. Actas de Seminario. FADEU PUC, Santiago, 2004, pp. 67-68.

20 PÉREZ, Fernando. Ob. Cit. p. 68.

21 ARISTÓTELES 1994

22 En agosto del 2012 el Colegio de Arquitectos dio a conocer un documento con una serie de recomendaciones técnicas en torno al mall de Castro, tras la jornada de reflexión de intervención urbana, y que congregó a especialistas a dialogar sobre su construcción. La carta señala la importancia de aprovechar la oportunidad de esta situación de crisis, para realizar un estudio que permita entender Chiloé en toda su complejidad, que luego se defina un plan de desarrollo sustentable integral para el archipiélago, que involucre toda la dimensión espacial del territorio. Respecto al mall en particular se sugiere implementar mitigaciones arquitectónicas orientadas a disminuir el impacto visual del edificio modificando su materialidad y su volumetría, y diseñar una plaza-mirador para la realización de eventos culturales y de recreación. Con una obra gruesa conclusa, las recomendaciones emitidas son una reacción tardía e insuficiente, con pocas posibilidades de generar cambios significativos en el diseño del edificio.

$23 \mathrm{Me}$ refiero al modelo de ciudad inspirada en el funcionalismo e instrumento de la productivad, detonada por la Revolución Industrial, propia del siglo XX y heredera de los C.I.A.M. 
minimizar u ocultar los efectos sociales del daño ocasionado; daño que tiende a ser permanente y corregido deficientemente. Muy raramente, en cambio, se plantea una hipótesis que cuestione la validez y legitimidad de tales procesos para el desarrollo y la convivencia ciudadana, que satisfaga las simples y profundas necesidades de los habitantes, en respeto al entorno natural y edificado. En este sentido, la reacción del Colegio de Arquitectos, algunas universidades, el Consejo de Monumentos Nacionales, e incluso ministros de gobierno, ante las imágenes del edificio difundidas por las redes sociales a principios del año 2012, constituye un respuesta significativa y bastante compartida, que expresa buena parte de las tendencias de opinión que cuestionarán nuestro actuar profesional en la construcción de la ciudad del siglo XXI.

En el panorama actual, la emergencia de una ciudadanía participativa, junto a nuevos procesos económicos y políticos, entre otros cambios, generan la necesidad de recuperar una visión pública de conjunto de la ciudad, frente a múltiples actuaciones particulares a escala local, y exigen nuevas miradas a las formas en que el territorio se ocupa y urbaniza. Una visión pública de conjunto de la ciudad significa recuperar la tradición en la que se caracterizó el ethos precisamente en el contexto de la polis griega ${ }^{24}$.

Es primordial, entonces, que mediante la experiencia de casos como éste logremos despertar en la profesión y en la comunidad, la conciencia de que Castro no es sólo de sus habitantes. De que el goce y respeto por su transformación y futuro, su imagen y funcionamiento, dependen de la voluntad de todos y no sólo de las autoridades, arquitectos o agentes inmobiliarios. Con ello lograremos también que la gente, los pobladores, reclamen por instancias permanentes que les permitan participar en la toma de decisiones que afectan su ciudad, en su planeación, en la previsión de errores, en la eliminación de carencias, y en definitva, en las herramientas para alcanzar una mejor calidad de vida.

En el caso del mall de Castro no podemos desconocer que parte de la responsabilidad es del Estado, porque a él le compete promover el bien común. Pero también hay responsabilidad de la comunidad, de los inversionistas, y nuestra, profesionales de la arquitectura, porque dejamos que el problema urbano sea un tema de la élite intelectual.

Finalmente, ¿existe algo que podamos denominar como una ética del arquitecto? Más que un principio, hay una cierta actitud ética. Fernando Pérez lo define como la necesaria noción de cuidado, en el doble sentido de cuidar y de prudente acercamiento. "Cuidado en el ejercicio del oficio que atiende a su radical referencia a otro. Trabajar con los medios de otros a través de otros y para otros ${ }^{25 "}$, dice. Es una disposición a actuar con atención, y a-tensión es la tensión hacia el otro. Habrá de exigirse atención a la forma que adquiere nuestra libertad en el ejercicio del oficio, y a los requerimientos de la realidad que la limitan y a través de ello la formalizan con rigor. Y que esa justeza en el pensar, actuar y dar forma en atención al otro, sean los fundamentos sobre los que se construyan ciudades más justas.

24 Como nos recuerda Anna Harendt: "Por naturaleza (physei) los hombres eran desiguales y se requería de una institución artificial, la polis, que gracias a su nomos, les hiciese iguales. La igualdad existía sólo en esta esfera específicamente política, donde los hombres se reunían como ciudadanos y no como personas privadas. La igualdad de la polis griega, su isonomía, era un atributo de la polis y no de los hombres, los cuales accedían a la igualdad en virtud de la ciudadanía, no en virtud del nacimiento". ARENDT, Hannah. Sobre la revolución. Revista de Occidente, Madrid, 1967.

25 PÉREZ 2004 


\section{Bibliografía}

ARENDT, Hannah. Sobre la revolución. Revista de Occidente, Madrid, 1967.

ARISTÓteleS. Ética de Nicómaco. Pentagrama, México, 2001.

ARISTÓTELES. Política. Ediciones Altaya, Barcelona, 1994.

BALCELLS, I., RIVERA, J.E., VIAL, J, PÉREZ, F. Ética, Ciudad y Arquitectura. Actas de Seminario. FADEU PUC, Santiago, 2004.

BROWN, Pete. Ética hacia la Empresa. Tecnos, Madrid, 1998.

CORTINA, Adela. Ética de la Empresa. Trotta, Madrid, 1999.

DEL SOL, Germán. "La ética detrás del oficio", columna publicada en

http://www.plataformaarquitectura.cl/2010/06/10/la-etica-detras-del-oficio/ del 10/06/2010, consultada al $20 / 11 / 2013$.

FOX, WARWICK (ed). Ethics and the built environment. Routledge, Londres, 2000.

KANT, IMMANUEL. Fundamento de la metafísica de las costumbres (1785). Tecnos, Madrid, 2005.

MORENO, Miguel. Historia de la Filosofía v.1. Universidad de Granada, Granada, 2010.

PÉREZ, Fernando. "Ética, Ciudad y Arquitectura" en BALCELLS, I., RIVERA, J.E., VIAL, J, PÉREZ, F. Ética, Ciudad y Arquitectura. Actas de Seminario. FADEU PUC, Santiago, 2004, p. 76

PULTAR, Mustafa. "The conceptual basis of building ethics" en FOX, W. (ed.). Ethics and the built environment. Routledge, Londres, 2000.

ROMERO, Martín. "Presidente del Colegio de Arquitectos: Si el marco legal es laxo, el inversionista inmobiliario puede hacer lo que quiera". Entrevista publicada en

http://colegioarquitectos.com/noticias/?p=4054 el 21/06/2013 consultado al 18/11/2013.

SÁNCHEZ V., Adolfo. Ética. Editorial Crítica, Barcelona, 1981. 